\title{
Erratum to: Strategies African-American Cancer Survivors Use to Overcome Fears and Fatalistic Attitudes
}

\author{
Jill B. Hamilton • Nakia C. Best • Kayoll V. Galbraith • \\ Valarie C. Worthy $\cdot$ Angelo D. Moore
}

Published online: 16 December 2014

(C) Springer Science+Business Media New York 2014

\section{Erratum to: J Canc Educ}

DOI 10.1007/s13187-014-0738-3

Due to an oversight, Dr. Angelo D. Moore's name was listed incorrectly (as L.A. Moore) in PubMed as well as in the article itself (L.A.D. Moore) Strategies African-American Cancer Survivors Use to Overcome Fears and Fatalistic Attitudes, JCED, September 2014, DOI 10.1007/s13187-014-0738-3.

The online version of the original article can be found at http://dx.doi.org/ 10.1007/s13187-014-0738-3.

J. B. Hamilton $(\bowtie)$

Department of Community-Public Health, School of Nursing, Johns

Hopkins University, 525 N. Wolfe Street, Baltimore, MD 21205 ,

USA

e-mail: jhamil32@jh.edu

N. C. Best $\cdot$ K. V. Galbraith

School of Nursing, University of North Carolina at Chapel Hill,

Carrington Hall, CB \#7460, Chapel Hill, NC 27599, USA

V. C. Worthy

Triangle Chapter, Sisters Network, Inc., Durham, NC 27707, USA

A. D. Moore

Center for Nursing Science and Clinical Inquiry, Womack Army

Medical Center, U.S. Army, 2817 Reilly Road, Fort Bragg, NC, USA 